\title{
Urinary gonadotrophin excretion in patients with ulcerative colitis and Crohn's disease treated with A.C.T.H. and corticosteroids
}

\author{
G. P. CREAN, J. A. LORAINE, E.T. BELL, W. I. CARD, AND W. SIRCUS \\ From the M.R.C. Clinical Endocrinology Research Unit, University of Edinburgh, and the \\ Gastro-Intestinal Unit, Western General Hospital, Edinburgh
}

EDITORIAL COMMENT A good clinical response to A.C.T.H. and corticosteroids is associated with a marked rise in the urinary excretion of human pituitary gonadotrophins.

It is generally believed that exogenously administered A.C.T.H. and corticosteroids suppress the secretion of endogenous A.C.T.H. and possibly also of thyroid-stimulating hormone and growth hormone (Ackerman, Smith, and Miller, 1961; Hartog, Gaafar, and Fraser, 1964; Graber, Ney, Nicholson, Island, and Liddle, 1965). However, information regarding the effect of these forms of treatment on pituitary gonadotrophic function is conflicting. In the reports of Maddock, Chase, and Nelson (1953), Lemon (1957), and Brown, Thorburn, and Crooks (1963) patients with a variety of diseases were studied; in the majority of subjects treatment with A.C.T.H. or corticosteroids caused a rise in the output of human pituitary gonadotrophins. On the other hand, Segaloff, Carabasi, Horwitt, Schlosser, and Murison (1954) observed a decrease in levels of pituitary gonadotrophins in a proportion of women with metastatic mammary carcinoma during treatment with corticosteroids. Sohval and Soffer (1951), who conducted their assays in patients suffering from disseminated lupus erythematosus and allied conditions, obtained inconsistent results bearing no obvious relationship to the clinical response to treatment.

This problem has been reinvestigated by conducting serial assays of pituitary gonadotrophins in patients with major intestinal conditions, especially ulcerative colitis and Crohn's disease, before, during, and following treatment with A.C.T.H. and synthetic corticosteroid analogues. In all subjects the effects of these forms of treatment on excretion of pituitary gonadotrophins have been correlated with the clinical response. The present communication, a preliminary account of which has been given else- where (Crean, Bell, Card, Loraine, and Sircus, 1963), reports the results obtained.

MATERIALS AND METHODS

COMPOUNDS ADMINISTERED Naturally occurring A.C.T.H. (corticotrophin, Armour) was given by the intramuscular route. Prednisolone (11 $\beta, 17 \alpha, 21$-trihydroxy-pregn-1,4diene-3,20-dione) and betamethazone (11 $\beta, 17 \alpha, 21$-trihydroxy-9 $\alpha$-fluoro-16 $\beta$-methylpregn-1,4-diene-3,20-dione) were administered orally.

PATIENTS Seventeen subjects were investigated. Clinical details, together with treatment and response in terms of excretion of pituitary gonadotrophins, are summarized in Tables I and II.

All the patients were in hospital during the initial period of study; in three $(1,5$, and 13$)$ assays were conducted on two occasions during separate periods of treatment.

ASSESSMENT OF CLINICAL RESPONSE The investigation of each patient was conducted in the form of a 'doubleblind' trial in which independent assessments were made of the therapeutic effect of A.C.T.H. and corticosteroids on the one hand and of the changes in excretion of pituitary gonadotrophins on the other. The therapeutic response of individual cases was determined as far as possible on objective evidence, but as might have been expected, some form of subjective clinical assessment had also to be made in certain instances. It was considered that the 'double-blind' method of assessing the results effectively eliminated any errors which might have arisen due to observer bias and which might have prejudiced the subjective clinical assessments.

Three categories of clinical response were recognized, namely, good response, partial response, and no response. It must be emphasized that this classification was made only on the basis of the changes observed during the 
period of investigation; the subsequent course of individual patients was not considered in the classification.

HORMONE ASSAY METHODS Estimations of human pituitary gonadotrophins in urine were performed by the method of Loraine and Brown (1959). The end point of the bioassay was the mouse uterus test, results being expressed in terms of the First International Reference Preparation for Human Menopausal Gonadotrophin (1st I.R.P.-H.M.G.) as H.M.G. units per 24-hour urine sample. The assay method measures 'total gonadotrophic activity' and is not specific for either follicle-stimulating hormone or luteinizing hormone. As employed in this Unit the technique has a high degree of precision, the index of precision $(\lambda)$ (Gaddum, 1933) being generally below 0.20 (SchmidtElmendorff, Loraine, and Bell, 1962).

In a limited number of patients urinary steroid assays were performed in addition to estimations of gonadotrophins. In such subjects total 17-hydroxycorticosteroids and total 17-oxosteroids were determined by the methods of Appleby, Gibson, Norymberski, and Stubbs (1955) and Vestergaard (1951), respectively. For the measurement of urinary oestrone, oestradiol and oestriol, the technique employed was that of Brown (1955). The term 'total oestrogens' (Figs. 1 and 8) denotes the sum of excretion values for these three compounds.

\section{RESULTS}

In Tables I and II changes in output of human pituitary gonadotrophins are related to clinical response. With respect to gonadotrophin excretion the term 'marked rise' indicates that the readings were above the normal range for the appropriate group of subjects while the term 'slight rise' denotes an increase in levels which was not outside this range. Normal ranges of output in the various age groups concerned are given elsewhere (Loraine and Bell, 1966).

It will be noted that of 11 patients in whom the clinical response was good (Table I) there was a marked rise in output of gonadotrophins in eight $(73 \%)$. On the other hand in four patients in whom a partial response was obtained (Table II) a marked rise in excretion was noted in only one of the seven treatment periods $(14 \%)$. In the three subjects who failed to respond levels of pituitary gonadotrophins remained within the appropriate normal range throughout.

Figures 1 to 9 show examples of the effect of treat-

TABLE I

\begin{tabular}{|c|c|c|c|c|c|c|c|}
\hline \multirow[b]{2}{*}{$\begin{array}{l}\text { Number } \\
\text { of } \\
\text { Patient }\end{array}$} & \multirow[b]{2}{*}{$\begin{array}{l}\text { Age } \\
\text { (years) }\end{array}$} & \multirow[b]{2}{*}{ Sex } & \multicolumn{4}{|c|}{ DETAILS OF PATIENTS SHOWING A GOOD RESPONSE TO TREATMENT } & \multirow[b]{2}{*}{$\begin{array}{l}\text { Effect of Treatment on } \\
\text { Excretion of Pituitary } \\
\text { Gonadotrophins }\end{array}$} \\
\hline & & & Diagnosis & Treatment & $\begin{array}{l}\text { Duration of } \\
\text { Treatment } \\
\text { (days) }\end{array}$ & $\begin{array}{c}\text { Total Dose } \\
\text { (i.u., mg.) }\end{array}$ & \\
\hline $1 \mathrm{a}$ & 22 & $\mathbf{M}$ & Crohn's disease & A.C.T.H. & 33 & 2,310 & Marked rise \\
\hline b & 23 & & & Betamethazone & & $118 \cdot 5$ & Marked rise \\
\hline 2 & 47 & $\mathbf{F}$ & Ulcerative colitis & Prednisolone & 36 & 1,910 & Marked rise \\
\hline 3 & 41 & $\mathbf{M}$ & Entero-colitis & - & - & - & Marked rise \\
\hline $5 a$ & 44 & $\mathbf{F}$ & Ulcerative colitis & A.C.T.H. & 31 & 1,900 & Slight rise \\
\hline b & 45 & & & A.C.T.H. & 35 & 1,830 & No effect \\
\hline 6 & 59 & $\mathbf{F}$ & Ulcerative colitis & A.C.T.H. & 22 & 1,920 & Marked rise \\
\hline 7 & 30 & $\mathbf{M}$ & Ulcerative colitis & A.C.T.H. & 44 & 3,740 & Marked rise \\
\hline 8 & 22 & $\mathbf{M}$ & Ulcerative colitis & Prednisolone & 33 & 1,640 & Marked rise \\
\hline 9 & 19 & $\mathbf{F}$ & Ulcerative colitis & Prednisolone & 41 & 1,070 & Marked rise \\
\hline 10 & 40 & $\mathbf{M}$ & Crohn's disease & Prednisolone & 564 & 7,125 & Marked rise \\
\hline 11 & 25 & $\mathbf{M}$ & Entero-colitis & Prednisolone & 131 & 2,640 & No effect \\
\hline
\end{tabular}

TABLE II

DETAILS OF PATIENTS SHOWING A PARTIAL OR NO RESPONSE TO TREATMENT

\begin{tabular}{|c|c|c|c|c|c|c|c|c|}
\hline Response & $\begin{array}{l}\text { Number } \\
\text { of } \\
\text { Patient }\end{array}$ & $\begin{array}{l}\text { Age } \\
\text { (years) }\end{array}$ & Sex & Diagnosis & Treatment & $\begin{array}{l}\text { Duration of } \\
\text { Treatment } \\
\text { (days) }\end{array}$ & $\begin{array}{l}\text { Total } \\
\text { Dose } \\
\text { (i.u., mg.) }\end{array}$ & $\begin{array}{l}\text { Effect of Treatment on } \\
\text { Excretion of Pituitary } \\
\text { Gonadotrophins }\end{array}$ \\
\hline Partial & $\begin{array}{l}12 \mathrm{~b} \\
13 \\
14 \\
15\end{array}$ & $\begin{array}{l}31 \\
15 \\
\\
15 \\
60\end{array}$ & $\begin{array}{l}\mathbf{M} \\
\mathbf{M} \\
\mathbf{M} \\
\mathbf{M}\end{array}$ & $\begin{array}{l}\text { Ulcerative colitis } \\
\text { Ulcerative colitis } \\
\text { Ulcerative colitis } \\
\text { Entero-colitis }\end{array}$ & $\begin{array}{l}\text { A.C.T.H. } \\
\text { Prednisolone } \\
\text { A.C.T.H. } \\
\text { Prednisolone } \\
\text { A.C.T.H. } \\
\text { A.C.T.H. } \\
\text { Prednisolone }\end{array}$ & $\begin{array}{l}41 \\
33 \\
26 \\
45 \\
63 \\
37 \\
47\end{array}$ & $\begin{array}{r}2,575 \\
1,640 \\
1,350 \\
1,420 \\
2,700 \\
2,540 \\
470\end{array}$ & $\begin{array}{l}\text { Slight rise } \\
\text { No effect } \\
\text { No effect } \\
\text { Marked rise } \\
\text { No effect } \\
\text { Slight rise } \\
\text { Slight rise }\end{array}$ \\
\hline None & $\begin{array}{l}12 \mathrm{a} \\
16 \\
17\end{array}$ & $\begin{array}{l}29 \\
34 \\
38\end{array}$ & $\begin{array}{l}\mathbf{M} \\
\mathbf{M} \\
\mathbf{F}\end{array}$ & $\begin{array}{l}\text { Ulcerative colitis } \\
\text { Entero-colitis } \\
\text { Ulcerative colitis, } \\
\text { Carcinoma of colon }\end{array}$ & $\begin{array}{l}\text { Prednisolone } \\
\text { A.C.T.H. } \\
\text { A.C.T.H. }\end{array}$ & $\begin{array}{l}96 \\
54 \\
19\end{array}$ & $\begin{array}{l}1,510 \\
4,740 \\
1,520\end{array}$ & $\begin{array}{l}\text { No effect } \\
\text { No effect } \\
\text { No effect }\end{array}$ \\
\hline
\end{tabular}


ment on hormone excretion in patients showing the three types of clinical response described above. It is apparent that in some of the subjects the control period before therapy with A.C.T.H. or corticosteroids was relatively short; this arose from the necessity on clinical grounds for commencing therapy as rapidly as possible. In group a (Figs. 1 to 5) the mean percentage increase in pituitary gonadotrophin excretion over control values during the period of treatment was 144. In group b (Figs. 6 and 7) and group c (Figs. 8 and 9) the corresponding figures were 39 and 50 respectively.

PATIENTS SHOWING A GOOD CLINICAL RESPONSE Thirteen investigations in 11 subjects were performed (Table I). In nine instances a marked rise in output of pituitary gonadotrophins occurred at some time during the period of observation. In four studies in three patients $(4,5$, and 11$)$ a good clinical response was observed in the presence of gonadotrophin levels which either rose slightly or were unaffected. Typical examples of the results obtained in this group are shown in Figures 1 to 5.

Patient 1 (Figs. 1 and 2) This man with Crohn's disease was studied during two courses of treatment. At the time of his first admission to hospital he showed considerable diarrhoea and weight loss, there being radiological evidence of extensive mucosal ulceration in the terminal ileum, caecum, and ascending colon. His symptoms improved markedly following commencement of therapy by A.C.T.H.; this was associated with a marked increase in body weight and restoration to normal of the radiological appearances of the small and large bowel.

Before treatment levels of pituitary gonadotrophins were within the normal range for a male subject (Loraine and Bell, 1966). A marked increase occurred during therapy, and one week after A.C.T.H. had been withdrawn an exceptionally high level of 208

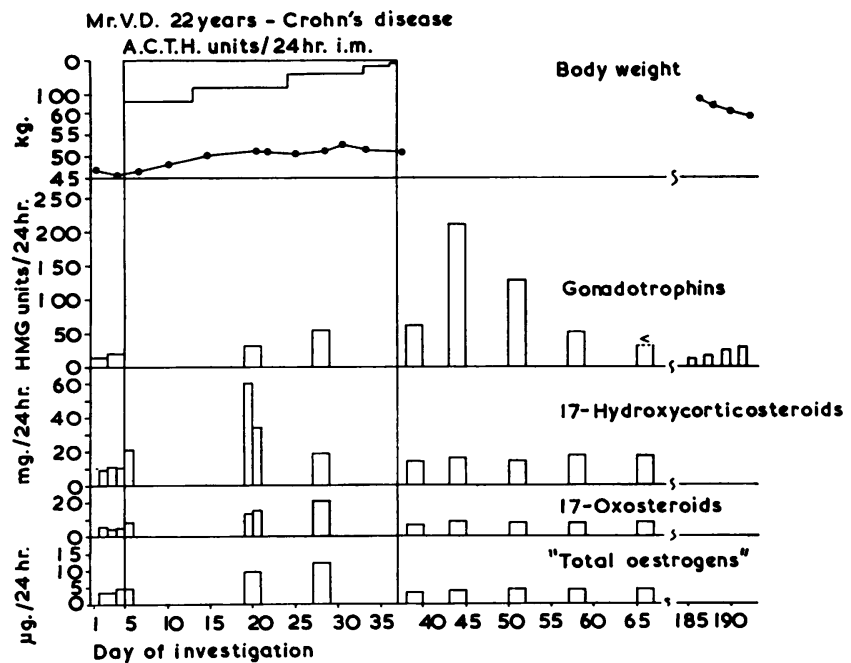

FIG. 1. The effect of A.C.T.H. on urinary hormone excretion in a patient with Crohn's disease (first study).

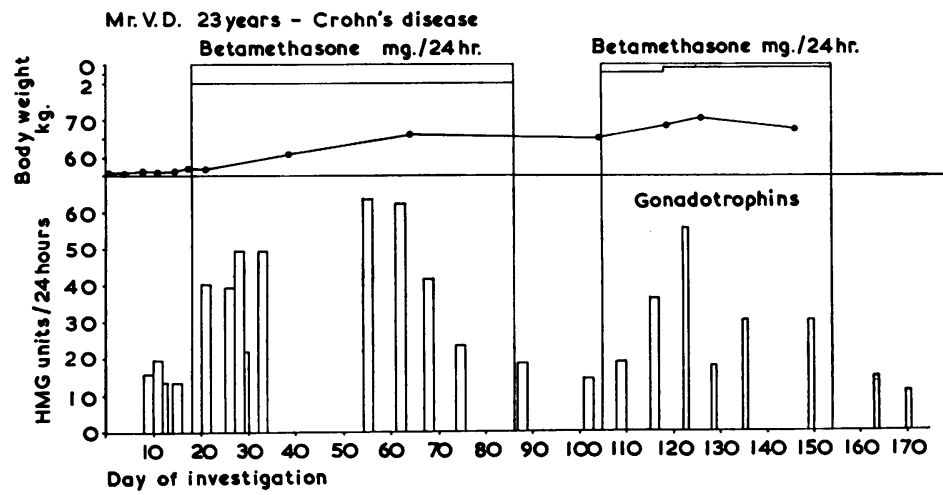

FIG. 2. The effect of betamethazone on urinary gonadotrophin excretion in a patient with Crohn's disease (second study). 
H.M.G. units per 24 hours was encountered. This reading would be abnormally high, even for a postmenopausal woman (Apostolakis and Loraine, 1960). Gonadotrophin excretion subsequently declined and had returned to control levels by the end of the investigation. During A.C.T.H. administration a marked rise in the urinary excretion of 17-hydroxycorticosteroids occurred indicating satisfactory adrenal stimulation. The increase in excretion values for 17-oxosteroids and 'total oestrogens' was less pronounced than for 17hydroxycorticosteroids.

The patient was re-admitted to hospital 12 months later because of severe rectal bleeding and was found to have steatorrhoea. He received two courses of betamethazone and on both occasions he showed a good clinical response.

The mean excretion of pituitary gonadotrophins before the first course of betamethazone was 16 H.M.G. units per 24 hours (Fig. 2). Excretion values increased rapidly following the initiation of therapy, the output almost doubling within 48 hours and reaching a peak of 64 H.M.G. units per 24 hours on days 55 and 56 of the study. Thereafter, gonadotrophin output decreased despite continued administration of the drug and had returned to control values at the time at which treatment was discontinued. During the second course of therapy excretion values again increased, reaching a maximum on day 123. Levels decreased subsequently and, at the completion of the investigation, were again within the normal range.

Patient 2 (Fig. 3) This post-menopausal woman was studied during her first major attack of ulcerative colitis. She had been receiving thyroxine for several years for hypothyroidism, and this drug was continued at a dose level of $0.3 \mathrm{mg}$. per day throughout the greater part of the period of investigation.
Before treatment the colonic mucosa was grossly abnormal, showing spontaneous bleeding, ulceration and oedema. No striking improvement occurred during the actual period of prednisolone administration and treatment was stopped on the 41st day of the study, although the disease was still active at that time. However, 28 days later the rectal mucosa had become virtually normal. It was considered that this patient had obtained a clinical remission of her disease during the period of investigation, although it was uncertain whether the response could be attributed directly to treatment with prednisolone.

Before the commencement of therapy the mean excretion of pituitary gonadotrophins was 136 H.M.G. units per 24 hours. This figure is at the upper end of the normal range for post-menopausal subjects (Apostolakis and Loraine, 1960). During and following treatment output increased to levels considerably above this range.

Patient 3 (Fig. 4) This patient with an enterocolitis of uncertain cause did not receive hormonal therapy during the period of investigation. He was studied during his first attack, the symptoms of which had been present continuously for six months. At the time of admission to hospital the main clinical features were diarrhoea, marked weight loss, intermittent fever and tachycardia. Sigmoidoscopic and radiological examination revealed an active ulcerative process involving the entire colon. He was treated with a high-caloric, high protein, low-residue diet, in association with vitamin, mineral and electrolyte supplements together with infusions of plasma. With this régime his condition improved markedly and at the time of his discharge from hospital, he had gained approximately $14 \mathrm{~kg}$. in body weight.

The first three assays of pituitary gonadotrophins were within the normal range for a male subject.

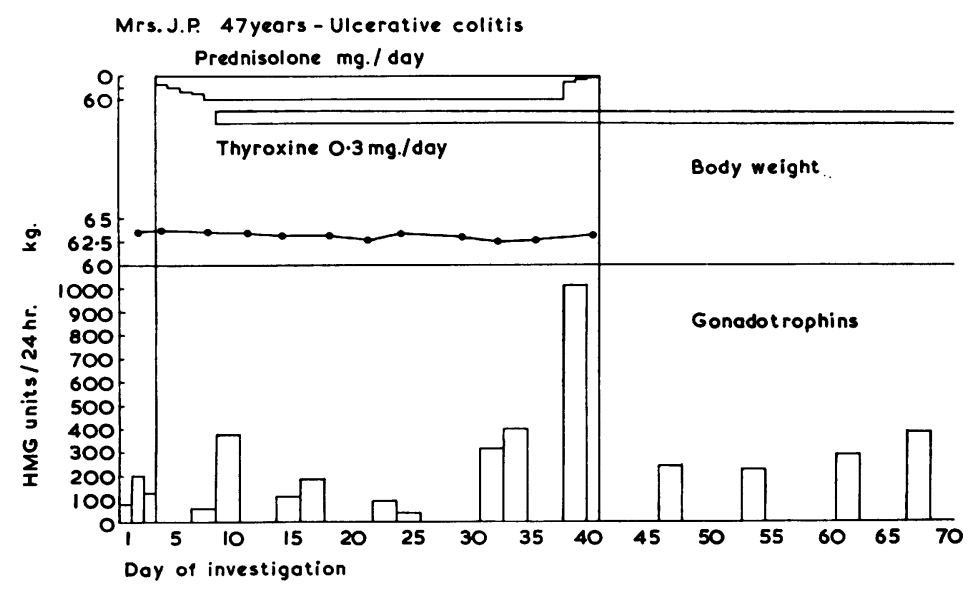

FIG. 3. The effect of prednisolone on urinary gonadotrophin excretion in a patient with ulcerative colitis. 


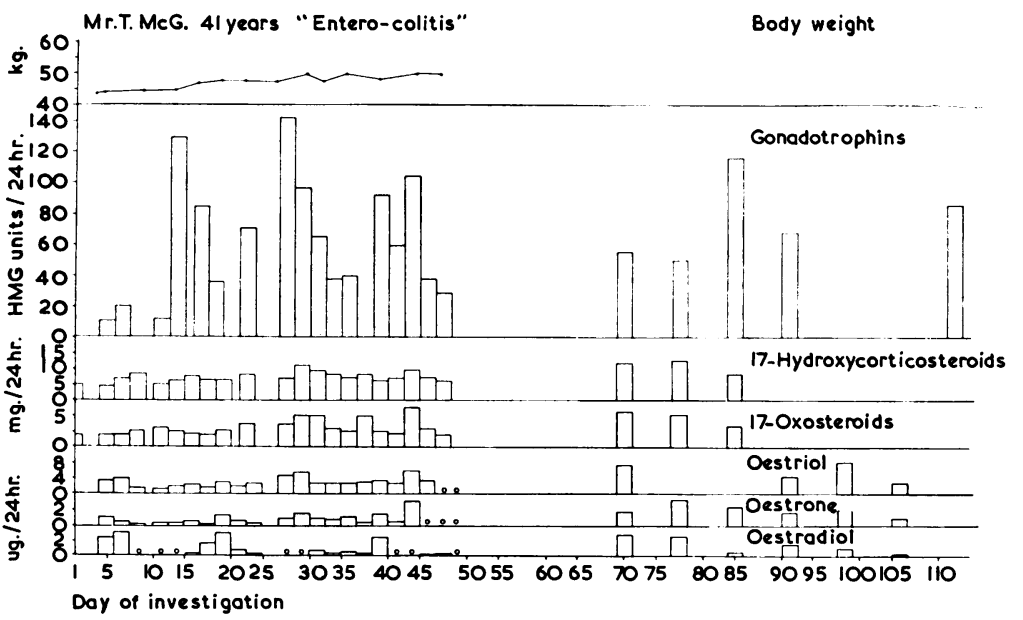

FIG. 4. Urinary hormone excretion in a patient with enterocolitis.
Thereafter, a marked increase in levels was noted, the highest value of 142 H.M.G. units per 24 hours being encountered on the 28 th and 29 th days. Readings remained high and were above the normal range throughout the remainder of the investigation. A slight rise in excretion values for 17-hydroxycorticosteroids, 17-oxosteroids and oestrogens occurred during the period of study.

Patient 4 (Fig. 5) This pre-menopausal patient suffered from Crohn's disease affecting principally the terminal ileum and descending colon; an ileotransverse colostomy with exclusion had been performed 13 months previously. She was almost moribund at the beginning of the present study, having lost $14 \mathrm{~kg}$. in body weight and showing severe diarrhoea and anaemia. She was treated with prednisolone and made a slow but definite recovery; she did not menstruate during the period of the investigation.

Gonadotrophin levels throughout were relatively low suggesting that the amenorrhoea was of pituitary rather than ovarian origin. Most of the readings were at the lower end of the normal range for a woman during reproductive life, but between days 60 and 150 and 320 and 340 higher levels were encountered.

PATIENTS SHOWING A PARTIAL CLINICAL RESPONSE There were four subjects in this category (Table II). The results obtained in two of these will be described in detail.

Patient 12 (Fig. 6) This was the second period of study in a male subject with ulcerative colitis who had previously been treated with prednisolone (Fig. 8) and had failed to respond. At the commencement of the present investigation he showed fever, moderate anaemia, and diarrhoea; sigmoidoscopic examination revealed widespread changes typical of ulcerative colitis. When treated with A.C.T.H. considerable improvement occurred in his condition, but the colonic mucosa remained abnormal.

Excretion of pituitary gonadotrophins before treatment was within the normal range for a male subject. Variable readings were encountered during therapy but at no time did abnormally high levels occur.

Patient 13 (Fig. 7) This boy suffered from

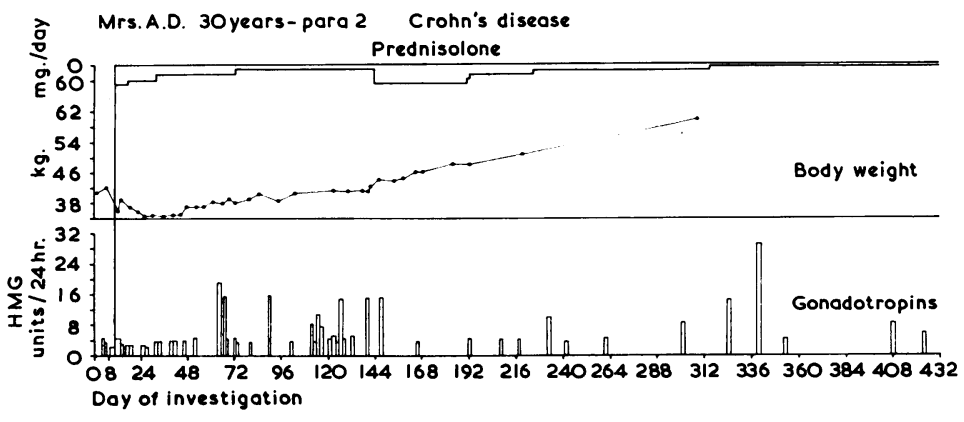

FIG. 5. The effect of prednisolone on urinary gonadotrophin excretion in a patient with Crohn's disease. 


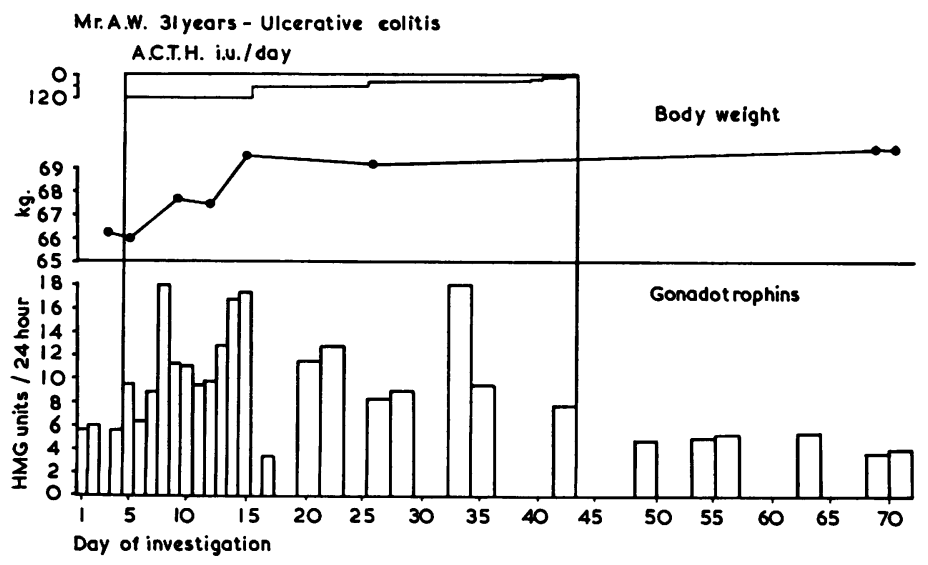

FIG. 6. The effect of A.C.T.H. on urinary gonadotrophin excretion in a patient with ulcerative colitis (second study).

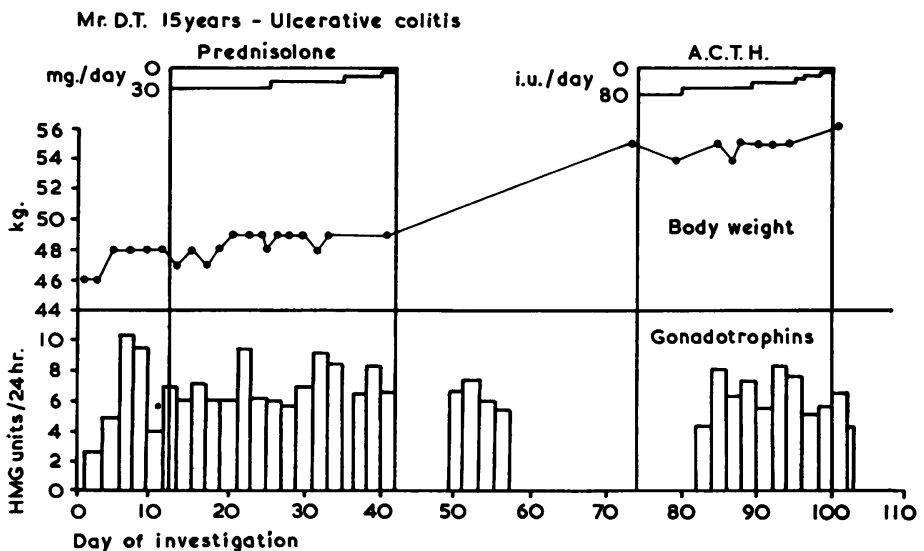

FIG. 7. The effect of prednisolone and of A.C.T.H. on urinary gonadotrophin excretion in a patient with ulcerative colitis.

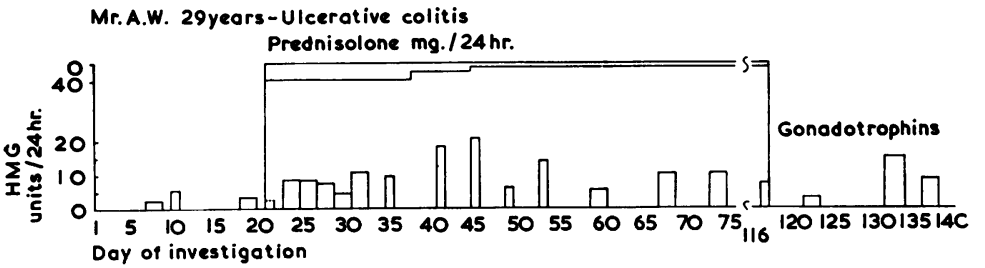

FIG. 8. The effect of prednisolone on urinary gonadotrophin excretion in a patient with ulcerative colitis (first study).

moderately severe ulcerative colitis which improved but did not completely remit during the three months of investigation. On admission to hospital the main features were low-grade fever, tachycardia, diarrhoea anaemia and weight loss. When treated with prednisolone his condition improved, and he was discharged from hospital on day $\mathbf{4 2}$ of the investigation, at which time the rectal mucosa appeared virtually normal on sigmoidoscopy. His symptoms recurred within a week of discharge, and he was readmitted on day 75 in a frank relapse of his condition. On this occasion he was treated with A.C.T.H. and again a partial remission was obtained. However, three weeks after the completion of the study the disease was again active.

Before treatment with prednisolone gonadotrophin levels were within the normal range for a male subject. Neither prednisolone nor A.C.T.H. caused any marked change in urinary output of pituitary gonadotrophins.

PATIENTS SHOWING No CliniCAL RESPONSE Three subjects are included in this category (Table II). Results in two will be described.

Patient 12 (Fig. 8) This was the first study in the man whose second period of investigation is shown 


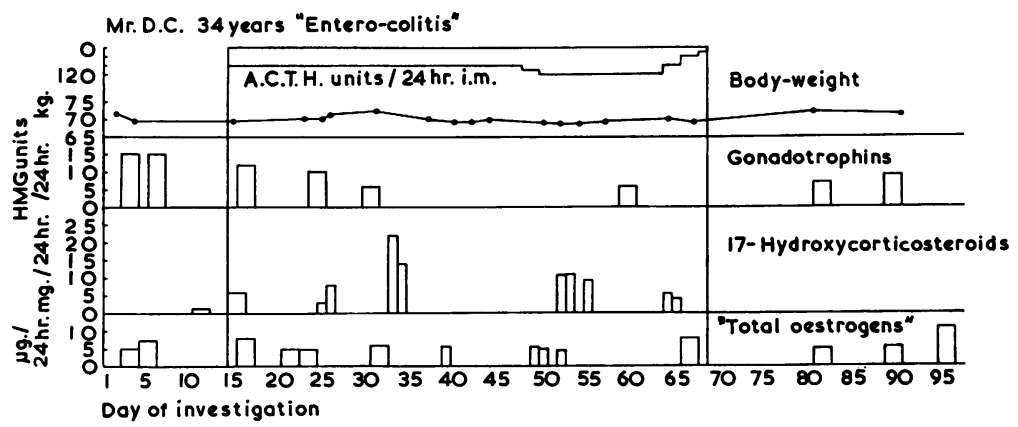

FIG. 9. The effect of A.C.T.H. on urinary hormone excretion in a patient with entero-colitis. in Figure 6. He had ulcerative colitis of moderate severity and was treated with prednisolone without any definite evidence of improvement.

Before treatment excretion of pituitary gonadotrophins was at the lower end of the normal range. Levels increased slightly during therapy but remained normal throughout.

Patient 16 (Fig. 9) This patient with enterocolitis of uncertain cause gave a six-month history of diarrhoea and weight loss. The large bowel was abnormal on sigmoidoscopic, histological and radiological examination. Treatment with A.C.T.H. produced no clinical improvement.

Before hormone administration gonadotrophin excretion was within the normal range for a male subject. During therapy there was no definite alteration in levels, but it is possible that changes may have occurred and were missed due to the relatively small number of assays performed during this time. A marked rise in excretion values for urinary 17-hydroxycorticosteroids was noted during treatment, suggesting that satisfactory adrenocortical stimulation had been produced.

\section{DISCUSSION}

The present investigation has demonstrated that, when patients with various intestinal diseases are treated with A.C.T.H., prednisolone, or betamethazone, different patterns of urinary gonadotrophin output are encountered. Some subjects showed high excretion values either during or immediately following therapy, while in others little or no change in levels was observed. In general, high readings occurred in patients who obtained a good clinical response while in cases showing a partial response or no response to treatment levels remained within the appropriate normal range. In all patients urinary gonadotrophin assays were performed before the initiation of therapy but in no case were such estimations found to be of value in predicting the response to treatment.

It might be postulated that the increased excretion of pituitary gonadotrophins observed in a proportion of the subjects studied resulted from a direct action of corticosteroids or A.C.T.H. on one or more of the processes by which gonadotrophic hormones are synthesized or secreted by the anterior pituitary, metabolized in the body, or handled by the kidneys. However, two main arguments appear to militate against such a hypothesis. In the first place, if a direct effect were the cause this might be expected to occur in all subjects receiving such treatment and might also be expected to bear a constant relationship to the total dose of A.C.T.H. or corticosteroids administered; in the investigation reported herein neither of these conditions obtained. Secondly, and probably more important, the findings in patient 3 (Fig. 4) in the present series indicate that a marked rise in urinary gonadotrophin excretion can occur in the absence of such therapy.

The close correlation observed between increased urinary output of pituitary gonadotrophins on the one hand and remission of disease on the other suggests an alternative hypothesis, namely, that the effect is due to the improvement in the general health of the patient. This hypothesis is supported by evidence already in the literature indicating that pituitary gonadotrophin excretion may rise during the phase of recovery from any severe illness, especially if the latter is associated with wasting. Such an increase has been observed in patients with severe malnutrition and with anorexia nervosa during refeeding (Zubirán and Gómez-Mont, 1953; Bell, Harkness, Loraine, and Russell, 1966). Moreover, Loraine, Douglas, Falconer, and Strong (1961) have noted that gonadotrophin output remains high or tends to rise in patients with recurrent mammary carcinoma whose disease showed a remission following bilateral adrenalectomy and oöphorectomy, whereas in women who obtained no improvement after these operations, excretion values either remained low or tended to fall. In an extension of the present study marked increases in output of pituitary gonadotrophins have been observed in two patients with severe pulmonary tuberculosis respond 
ing satisfactorily to chemotherapy and in one woman recovering from total procto-colectomy performed for severe ulcerative colitis.

The effects of gross nutritional changes on the secretion of gonadotrophic hormones in experimental animals also provide some support for the hypothesis adopted. It is now well established that a marked degree of gonadal atrophy may occur as a result of malnutrition in various animal species, including rats and guinea-pigs, despite the fact that the gonadotrophins are present in the pituitary gland in normal or even in increased amounts. It is also known that the gonadal atrophy which accompanies severe malnutrition may be rapidly corrected on the resumption of a normal diet (Meites, 1953; Meites and Reed, 1949; Rinaldini, 1949; Pearse and Rinaldini, 1950; see also Leathem, 1961; Chester Jones and Ball, 1962, for reviews). Various explanations can be suggested for these findings, including storage and subsequent release of gonadotrophic hormones, alterations in their rate of production following refeeding and changes in the hypothalmic control of the anterior pituitary gland.

The precise mechanism responsible for the increase in excretion of pituitary gonadotrophins in patients with intestinal diseases is not at present clear. Presumably, however, one or more of the explanations listed above could account for the results obtained. In the study reported herein pituitary function may have been influenced either by A.C.T.H. or corticosteroid therapy or by the complex changes which may be presumed to accompany recovery from a severe wasting illness. It has not been possible in the present investigation to separate these two factors and to determine the causative mechanism. However, such a separation might be more readily achieved by estimating levels of pituitary gonadotrophins in two other groups of subjects, the first receiving hormonal therapy for diseases such as rheumatoid arthritis and asthma in which nutritional factors are generally of relatively little importance, and the second, patients with a severe debilitating illness, e.g., tuberculosis or malabsorption, who are being treated by methods other than hormone administration. Studies of this type are currently in progress at this Unit and the results obtained will be reported in subsequent papers.

\section{SUMMARY}

The effect of A.C.T.H. and corticosteroids on the urinary excretion of human pituitary gonadotrophins has been investigated in 17 patients with intestinal disorders, especially ulcerative colitis and Crohn's disease.

In general, a good clinical response to these forms of treatment is associated with a marked rise in pituitary gonadotrophin output often to levels considerably above the appropriate normal range. On the other hand, in patients showing a partial response or no response, there is little or no effect on gonadotrophin excretion.

It is suggested that the rise in output of pituitary gonadotrophins in patients responding well to treatment is due to an improvement in general health.

Assays of pituitary gonadotrophins are not of value in predicting the response of patients with intestinal disorders to treatment with A.C.T.H. or corticosteroids.

In the performance of the assays the skilled assistance of many technicians at the Clinical Endocrinology Research Unit was much appreciated.

\section{REFERENCES}

Ackerman, N. B., Smith, R. W., Jr., and Miller, J. M. (1961). Interactions of hydrocortisone and thyrotropin on thyroid secretion of intact dogs. Metabolism, 10, 27-40.

Apostolakis, M., and Loraine, J. A. (1960). Renal clearance of pituitary gonadotrophins in postmenopausal women. J. clin. Endocr., 20, 1437-1444.

Appleby, J. I., Gibson, G., Norymberski, J. K., and Stubbs, R. D. (1955). Indirect analysis of corticosteroids. 1. The determination of 17-hydroxycorticosteroids. Biochem. J., 60, 453-460.

Bell, E. T., Harkness, R. A., Loraine, J. A., and Russell, G. F. M. 1966). Hormone assay studies in patients with anorexia nervosa Acta endocr. $(K b h), 51,140-148$.

Brown, J. B. (1955). A chemical method for the determination of oestriol, oestrone and oestradiol in human urine. Biochem. $J$. 60, 185-193.

Brown, P. S., Thorburn, A. R., and Crooks, J. (1963). Urinary gonadotrophin excretion during treatment with corticotrophin. $J$. Endocr., 28, 125-126.

Chester Jones, I., and Ball, J. N. (1962). Ovarian-pituitary relationships. In The Ovary, edited by Sir Solly Zuckerman, A. M. Mandl and P. Eckstein, vol. 1, pp. 361-434, Academic Press, New York and London.

Crean, G. P., Bell, E. T., Card, W. I., Loraine, J. A., and Sircus, W. (1963). The effect of adrenocorticotrophic hormone and corticosteroids on pituitary function in patients with ulcerative colitis and regional ileitis. $J$. Endocr., 26, 10-11P.

Gaddum J H. (1933). Reports on Biological Standards. III. Methods of biological assay depending on a quantal response. Spec. Rep. Ser. med. Res. Coun. (Lond.), 183.

Graber, A L., Ney, R. L., Nicholson, W. E., Island, D. P., and Liddle G. W. (1965). Natural history of pituitary-adrenal recovery following long-term suppression with cortisosteroids. J. clin. Endrocr., 25, 11-16.

Hartog, M., Gaafar, M. A., and Fraser, R. (1964). Effect of corticosteroids on growth hormone. Lancet, 2, 376-378.

Leathem, J. H. (1961). Nutritional effects on endocrine secretions. In Sex and Internal Secretions, edited by W. C. Young, 3rd Ed. vol. I, pp. 666-704. Baillière, Tindall \& Cox, London.

Lemon, H. M. (1957). Cortisone-thyroid therapy of metastatic mammary cancer. Ann. intern. Med., 46, 457-484.

Loraine, J. A., and Bell, E. T. (1966). Hormone Assays and their Clinical Application, 2nd ed., ch. II. Livingstone, Edinburgh.

— ation of gonadotrophins in the urine of non-pregnant subjects. J. Endocr., 18, 77-84.

—, Douglas, M., Falconer, C. W. A., and Strong, J. A. (1961) Urinary gonadotrophin excretion in relation to the treatment of mammary carcinoma by bilateral adrenalectomy and oöphorectomy. Mem. Soc. Endocrin., 10, 150-155.

Maddock, W. O., Chase, J. D., and Nelson, W. O. (1953). The effects of large doses of cortisone on testicular morphology and urinary gonadotrophin, estrogen and 17-ketosteroid excretion. J. Lab. clin. Med., 41, 608-614. 
Meites, J. (1953). Relation of nutrition to endocrine-reproductive functions. Iowa St. Coll. J. Sci., 28, 19-44.

- , and Reed. J. O. (1949). Effects of restricted feed intake in intact and ovariectomised rats on pituitary lactogen and gonadotrophin. Proc. Soc. exp. Biol. (N.Y.), 70, 513-516.

Pearse, A. G. E., and Rinaldini, L. M. (1950). Histochemical determination of gonadotrophin in the rat hypophysis. Brit. J. exp. Path., 31, 540-544.

Rinaldini. L. M. (1949). Effect of chronic inanition on the gonadotrophic content of the pituitary gland. J. Endocr., 6, 54-62.

Segaloff, A., Carabasi, R., Horwitt, B. N., Schlosser, J. V., and Mut ison, P. J. (1954). Hormonal therapy in cancer of the breast.
VI. Effect of A.C.T.H. and cortisone on clinical course and hormonal excretion. Cancer, (Philad.), 7, 331-334.

Schmidt-Elmendorff, H., Loraine, J. A., and Bell, E. T. (1962). Studies on the biological activity of various gonadotrophin preparations. J. Endocr., 24, 349-357.

Sohval, A. R., and Soffer, L. J. (1951). The influence of cortisone and adrenocorticotropin on urinary gonadotrophin excretion. $J$. clin. Endocr., 11, 677-687.

Vestergaard, P. (1951). Rapid micro-modification of the Zimmermann Callow procedure for the determination of 17 -ketosteroids in urine. Acta endocr., $(K b h), 8,.193-214$.

Zubirán, S., and Gómez-Mont, F. (1953). Endocrine disturbances in chronic human malnutrition. Vitam. and Horm., 11, 97-132. 